\title{
Ranch-Level Economic Impacts of Predation in a Range Livestock System
}

\section{By Benjamin S. Rashford, Thomas Foulke, and David T. Taylor}

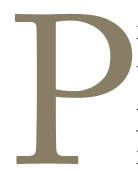
redation can impose significant costs on agricultural producers in range livestock systems. Livestock producers in the western United States have experienced predation on their herds since domestic livestock were introduced into the region. Early efforts to control predators were often initiated by individual ranchers or small local groups. The first federal involvement in wildlife damage control in the United States occurred in 1885. By 1915, Congress was appropriating funds for federal predator control operations directed at wolves and coyotes. In 1931, Congress passed the Animal Damage Control Act authorizing the control of injurious animals. This act is still in effect today. Today, USDA's Wildlife Services, state and local agencies, and livestock producers work cooperatively to manage predators.

Despite predator control efforts, Western livestock producers still experience significant predations losses. Wyoming's agricultural sector lost 4,000 cattle and calves and 24,000 sheep and lambs to all predators during $2005 .{ }^{1}$ The market value of this lost livestock was nearly US\$4.0 million. Despite significant aggregate financial impacts, there is little research on the ranch-level economic impacts of predation.

Predators can reduce ranch profitability through three primary mechanisms: 1) increased livestock death loss, 2) reduced livestock weaning weights, and 3) increased ranch labor and management costs. We use a mathematical ranch model of a representative cow-calf operation in western Wyoming to simulate the effects of these three predation mechanisms on ranch profitability.

\section{Simulating Predation Impacts}

We use a computerized ranch model to simulate the economic effects of increased death loss, decreased weaning weights, and increased variable costs. A multiyear linear programming framework, originally developed by Torell et al., ${ }^{2}$ is used to determine the herd size that maximizes profits and the optimal grazing strategy for each year given a cattle price scenario. We also report annual livestock sales and ranch income associated with the outcome. The results from the first-year outcome are used as starting conditions for the second year. We repeat this process for 40 years with optimal production levels chosen to maximize the net present value (the value in current dollars of revenues less costs) of ranch profits for each year. Because ranches face fluctuating cattle prices, the model uses the average from a randomized set of 100 prices that ranchers would likely face over the 40-year planning horizon (i.e., a Monte-Carlo simulation with 4,000 iterations per predator scenario-100 prices per year for 40 years).

The ranch modeling framework discussed above was modified with assistance from the original authors to create the Western Wyoming Grazing Model (WWGM), which reflects production characteristics of cow-calf operations in western Wyoming (Table 1). ${ }^{3,4}$ We adjusted the parameters in the model to reflect changes in death loss, weaning weights, and variable costs. The 40-year model was then rerun for each scenario. The results we report below are the average production and profit over the distribution of cattle prices.

\section{Increased Death Loss}

The majority of predation affects calves. Predators can increase calf death loss rates in summer pastures to as high as $12 \%$, as compared to $2 \%$ with no predation (A. P. Sommers, C. C. Price, C. D. Urbigkit, and E. M. Pertersen, unpublished data, 2008). ${ }^{5,6}$ We simulated the impacts of increased death loss on productivity and profits by adjusting the death loss ratios for calves in the WWGM. The baseline scenario assumes a $4 \%$ death loss ratio for calves-2\% death loss during summer grazing on public land and $2 \%$ for the rest of the year. Alternative death loss ratios of $6 \%, 8 \%$, and $10 \%$ are simulated in three additional runs to capture the potential range of predation impacts.

The ranch has net livestock returns (exclusive of fixed costs) of $\$ 65,172$ and ranch profits of $\$ 27,822$ in the 
Table 1. Baseline characteristics and assumptions for the representative ranch model

\begin{tabular}{|c|c|c|}
\hline \multicolumn{1}{|c|}{ Characteristic } & Quantity & $\begin{array}{c}\text { Productivity } \\
\text { assumptions }\end{array}$ \\
\hline Land base & & \\
\hline Public lease (AUMs) & 4,185 & \\
\hline Private lease (AUMs) & 224 & \\
\hline Deeded range (AUMs) & 1,076 & \\
\hline Hay meadow (tons) & 793 & 1.5 tons/acre \\
\hline Base herd & & \\
\hline Brood cows & 510 & \\
\hline Replacement heifers & 100 & \\
\hline AUM indicates animal unit month.
\end{tabular}

baseline scenario (Table 2). There are 610 bred cows (including both brood cows and first-calf heifers), which produce 569 calves (accounting for conception rates and death loss). The ranch sells 169 tons of hay. As death loss increases, ranch profits decrease due to the decrease in the number of calves available for sale. At a $6 \%$ death loss (equivalent to approximately nine additional calves lost to predation over the baseline), herd size declines marginally to 600 bred cows. However, it is economically optimal to wean fewer calves and to retain additional heifer calves to maintain herd numbers. The decrease in weaned calves reduces net livestock returns and ranch profits; however, the decrease in overall herd size allows an additional 15 tons of hay to be sold, which offsets some of the potential losses. Net livestock returns decrease by a manageable $8.3 \%$. Ranch profits, in contrast, decrease by approximately $20 \%$ because fixed costs are unchanged and must be absorbed by fewer marketed calves.

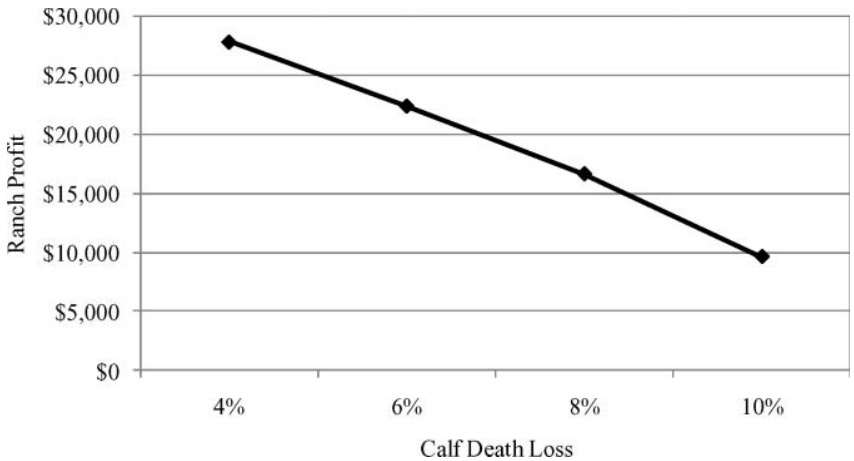

Figure 1. Effect of death loss on ranch profits estimated with a ranchlevel mathematical programming model. Death loss is measured as the percentage of calves killed, with an assumed baseline death loss of $4 \%$.

When we set calf death loss at $8 \%$ (equivalent to approximately 12 additional calves lost to predation over the baseline), herd size decreases $3.6 \%$ from the baseline to 588 bred cows. Hay sales increase by 35 tons. Though the increase in hay sales offsets some of the profit reduction from reduced calf sales, ranch profits still decrease from the baseline by over $40 \%$.

In the most extreme scenario, in which we increased calf death loss to $10 \%$ (equivalent to approximately 19 additional calves lost to predation over the baseline), the optimal herd size decreases by $7.2 \%$ from the baseline, and the ranch sells an additional 70 tons of hay. As a result of the decrease in marketed calves, ranch profits decrease by over $65 \%$. At this level of death loss, the ranch begins to struggle with the tradeoff between generating the returns required to cover annual variable costs and the need to maintain a cow herd sufficient for long-run viability.

Overall, ranch profit decreases at an increasing rate as the level of death loss increases (Fig. 1). Increased death loss also increases income variability as seen by the increase in

\section{Table 2. Simulation results for increased calf death loss scenario}

\begin{tabular}{|c|c|c|c|c|c|c|}
\hline Death loss & $\begin{array}{l}\text { Net livestock } \\
\text { returns (US\$) }\end{array}$ & $\begin{array}{c}\text { Average annual } \\
\text { profit (US\$) }\end{array}$ & $\%$ negative years & Cow herd & Calves & $\begin{array}{l}\text { Tons of } \\
\text { hay sold }\end{array}$ \\
\hline Baseline (4\%) & $\$ 65,172$ & $\$ 27,822$ & $32 \%$ & 610 & 569 & 169 \\
\hline $6 \%$ & $\$ 59,741$ & $\$ 22,391$ & $35 \%$ & 600 & 560 & 184 \\
\hline $8 \%$ & $\$ 53,993$ & $\$ 16,643$ & $39 \%$ & 588 & 548 & 204 \\
\hline \multirow[t]{2}{*}{$10 \%$} & $\$ 46,984$ & $\$ 9,634$ & $44 \%$ & 566 & 529 & 239 \\
\hline & \multicolumn{6}{|c|}{$-------------------\quad \%$ change from baseline } \\
\hline $6 \%$ & $-8.33 \%$ & $-19.52 \%$ & $11.4 \%$ & $-1.64 \%$ & $-1.58 \%$ & $8.88 \%$ \\
\hline $8 \%$ & $-17.15 \%$ & $-40.18 \%$ & $24.1 \%$ & $-3.61 \%$ & $-3.69 \%$ & $20.70 \%$ \\
\hline $10 \%$ & $-27.91 \%$ & $-65.37 \%$ & $40.4 \%$ & $-7.21 \%$ & $-7.03 \%$ & $41.42 \%$ \\
\hline \multicolumn{7}{|c|}{$\begin{array}{l}\text { "Net livestock returns" are returns from livestock sales less variable costs (excludes fixed costs). } \\
\text { "\% negative years" is the proportion of the } 40 \text { years simulated that profits are negative. } \\
\text { "Cow herd" represents all cows that have calved, including brood cows and first-calf heifers. }\end{array}$} \\
\hline
\end{tabular}


Table 3. Sale weights (pounds) used to simulate potential predator impacts on calf weaning weights

\begin{tabular}{|c|c|c|c|c|c|}
\hline Calves & Baseline & $\mathbf{1} \%$ & $\mathbf{3} \%$ & $\mathbf{5 \%}$ & $\mathbf{1 0} \%$ \\
\hline Steer calves & 440 & 436 & 427 & 418 & 396 \\
\hline Heifer calves & 390 & 386 & 378 & 371 & 351 \\
\hline
\end{tabular}

the percentage of years with negative profit (Table 2, column 4). In the baseline scenario, an average of three in 10 years (32\%) generate negative profit for the ranch. At a 10\% death loss, the operation experiences negative profits in four out of 10 years, on average. This level of income variability may significantly increase the chance of business insolvency.

\section{Reduced Weaning Weights}

Weaning weights are important to ranch profitability because they affect the gross returns on marketed calves. Research suggests a link between predation, or the stress caused by the presence of predators, and weaning weights; ${ }^{7}$ however, no definitive analysis is known to exist. Anecdotally, producers suggest that predator-induced stress can have an effect on calf weaning weights. We model this potential effect by reducing the sale weight of calves in the WWGM by $1 \%, 3 \%, 5 \%$, and $10 \%$ from the baseline (Table 3). The baseline weights are average weights of steer and heifer calves consistent with western Wyoming statistics.

Profits decrease steadily from the baseline of $\$ 27,822$ to $\$ 16,958$ as weaning weights are reduced by $1 \%$ to $5 \%$ (Table 4). When the reduction in weaning weights increases from $5 \%$ to $10 \%$, however, profit decreases substantially and becomes negative (a loss) on average. At a $10 \%$ reduction in

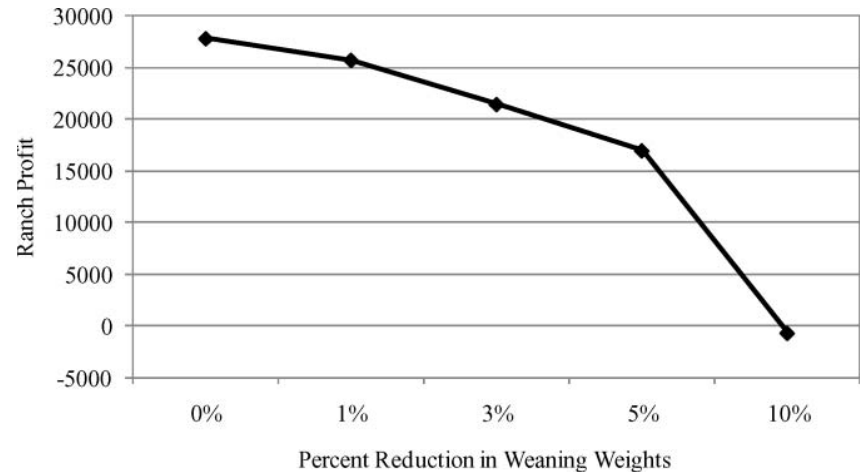

Figure 2. Effect of reduced weaning weights on ranch profits estimated with a ranch-level mathematical programming model. Percent reductions in weaning weights measure potential predation-induced changes relative to the modeled baseline $(0 \%)$.

weaning weights the revenue from selling 523 calves and 252 tons of hay rarely covers fixed and variable costs, and thus the ranch regularly incurs a loss. Similar to the death loss scenarios, the ranch optimally reduces herd size to adjust for reduced calf profitability and sells more hay as weaning weights decrease.

Figure 2 displays how profits decline steadily through a $5 \%$ reduction in weaning weight and then drop off precipitously to negative profits when weaning weights are reduced by $10 \%$. Income variability further indicates profit effects of reduced weaning weights. In the baseline, negative years occur $32 \%$ of the time. The $1 \%, 3 \%$, and $5 \%$ reduction in weaning weight scenarios show a steady, but moderate increase in the percentage of negative years. After 5\%, however, the rate of increase in income variability, and thus the reduction in average profits, increases considerably. At a $10 \%$ reduction in average weaning weights, the ranch has a $51 \%$ chance of incurring a loss in any given year. This is

\section{Table 4. Simulation model results for reduced weaning weights scenario}

\begin{tabular}{|c|c|c|c|c|c|c|}
\hline Scenario & $\begin{array}{l}\text { Net livestock } \\
\text { returns (US\$) }\end{array}$ & $\begin{array}{l}\text { Average annual } \\
\text { profit (US\$) }\end{array}$ & $\%$ negative years & Cow herd & Calves & $\begin{array}{l}\text { Hay sold } \\
\text { (tons) }\end{array}$ \\
\hline Baseline & $\$ 65,172$ & $\$ 27,822$ & $32 \%$ & 610 & 569 & 169 \\
\hline $1 \%$ reduction & $\$ 63,083$ & $\$ 25,733$ & $33 \%$ & 607 & 567 & 200 \\
\hline $3 \%$ reduction & $\$ 58,800$ & $\$ 21,450$ & $36 \%$ & 600 & 560 & 185 \\
\hline $5 \%$ reduction & $\$ 54,308$ & $\$ 16,958$ & $39 \%$ & 591 & 552 & 200 \\
\hline \multirow[t]{2}{*}{$10 \%$ reduction } & $\$ 36,622$ & $-\$ 727$ & $51 \%$ & 559 & 523 & 252 \\
\hline & \multicolumn{6}{|c|}{$-------------------\%$ change from base model -------------------} \\
\hline $1 \%$ reduction & $-3.2 \%$ & $-7.5 \%$ & $4.4 \%$ & $-0.5 \%$ & $-0.4 \%$ & $18.3 \%$ \\
\hline $3 \%$ reduction & $-9.8 \%$ & $-22.9 \%$ & $13.5 \%$ & $-1.6 \%$ & $-1.6 \%$ & $9.5 \%$ \\
\hline $5 \%$ reduction & $-16.7 \%$ & $-39.0 \%$ & $23.4 \%$ & $-3.1 \%$ & $-3.0 \%$ & $18.3 \%$ \\
\hline $10 \%$ reduction & $-43.8 \%$ & $-102.6 \%$ & $62.3 \%$ & $-8.4 \%$ & $-8.1 \%$ & $49.1 \%$ \\
\hline
\end{tabular}


Table 5. Grazing costs (US\$/AUM) by land type used to simulate increased variable costs resulting from predation

\begin{tabular}{|l|c|c|c|c|c|}
\hline \multicolumn{1}{|c|}{ Land type } & Base & $\mathbf{5 \%}$ & $\mathbf{1 0 \%}$ & $\mathbf{2 0 \%}$ & $\mathbf{3 0 \%}$ \\
\hline BLM & $\$ 7.19$ & $\$ 7.55$ & $\$ 7.91$ & $\$ 8.63$ & $\$ 9.35$ \\
\hline USFS & $\$ 9.46$ & $\$ 9.93$ & $\$ 10.41$ & $\$ 11.35$ & $\$ 12.30$ \\
\hline State & $\$ 10.79$ & $\$ 11.33$ & $\$ 11.87$ & $\$ 12.95$ & $\$ 14.03$ \\
\hline Private lease & $\$ 13.25$ & $\$ 13.91$ & $\$ 14.58$ & $\$ 15.90$ & $\$ 17.23$ \\
\hline Deeded range & $\$ 3.25$ & $\$ 3.41$ & $\$ 3.58$ & $\$ 3.90$ & $\$ 4.23$ \\
\hline
\end{tabular}

AUM indicates animal unit month; BLM, Bureau of Land Management; and USFS, US Forest Service.

a $20 \%$ increase over the baseline and is sufficient to threaten the long-run viability of the ranch.

\section{Increased Variable Costs}

Ranching operations face two types of costs, variable and fixed. Variable costs increase with each additional unit of production. In cow-calf operations, variable costs include hay and other feeds, veterinary costs, fuel, equipment repair, trucking, and labor. Fixed costs, in contrast, do not vary with the production level, and may include taxes, insurance, depreciation, and loan payments. Operations subject to heavy predation may incur increased herding costs, possibly having to add additional herders if conditions warrant. Additionally, increased variable costs could result from the need to document predation incidents, increased veterinary services, and the need to check on and move animals more frequently.

We investigate the effects of increased variable costs by increasing the costs of using different grazing land types in the WWGM. The model incorporates labor and management and other variable costs into the per-animal unit month (AUM) cost for each grazing land type in the model. Therefore, increasing grazing cost can be used as a proxy for increased variable costs. Because no consistent estimates exist for variable costs directly related to predator management activities on western US cow-calf operations, we simply increase grazing costs by $5 \%, 10 \%, 20 \%$, and $30 \%$ to evaluate potential effects on profitability (Table 5). These percentage changes imply an annual increase in variable cost of approximately \$0.50/AUM, \$1.00/AUM, \$1.75/AUM, and \$2.65/AUM, respectively. The largest (30\%) increase in variable cost is consistent with significant management changes, such as substantially increasing herding activities during the grazing season. ${ }^{8}$

With increased variable costs, net livestock returns decrease over the range of results by nearly 30\% from $\$ 65,172$ to $\$ 47,127$ (Table 6). Ranch profits decline by $65 \%$, from $\$ 27,822$ to $\$ 9,777$ (Fig. 3) and the cow herd is

\section{Table 6. Simulation model results for increased variable costs scenario}

\begin{tabular}{|c|c|c|c|c|c|c|}
\hline Scenario & $\begin{array}{l}\text { Net livestock } \\
\text { returns (US\$) }\end{array}$ & $\begin{array}{c}\text { Average annual } \\
\text { profit (US\$) }\end{array}$ & $\%$ negative years & Cow herd & Calves & $\begin{array}{l}\text { Hay sold } \\
\text { (tons) }\end{array}$ \\
\hline Baseline & $\$ 65,172$ & $\$ 27,822$ & $32 \%$ & 610 & 569 & 169 \\
\hline $5 \%$ increase & $\$ 62,496$ & $\$ 25,146$ & $34 \%$ & 604 & 564 & 179 \\
\hline $10 \%$ increase & $\$ 59,728$ & $\$ 22,378$ & $36 \%$ & 596 & 557 & 192 \\
\hline $20 \%$ increase & $\$ 53,952$ & $\$ 16,602$ & $40 \%$ & 575 & 537 & 227 \\
\hline \multirow[t]{2}{*}{$30 \%$ increase } & $\$ 47,127$ & $\$ 9,777$ & $45 \%$ & 539 & 504 & 285 \\
\hline & \multicolumn{6}{|c|}{$-------------------\%$ change from base model -------------------} \\
\hline $5 \%$ increase & $-4.1 \%$ & $-9.6 \%$ & $6.0 \%$ & $-1.0 \%$ & $-0.9 \%$ & $5.9 \%$ \\
\hline $10 \%$ increase & $-8.4 \%$ & $-19.6 \%$ & $13.1 \%$ & $-2.3 \%$ & $-2.1 \%$ & $13.6 \%$ \\
\hline $20 \%$ increase & $-17.2 \%$ & $-40.3 \%$ & $26.4 \%$ & $-5.74 \%$ & $-5.62 \%$ & $34.3 \%$ \\
\hline $30 \%$ increase & $-27.7 \%$ & $-64.9 \%$ & $42.7 \%$ & $-11.64 \%$ & $-11.42 \%$ & $68.6 \%$ \\
\hline
\end{tabular}




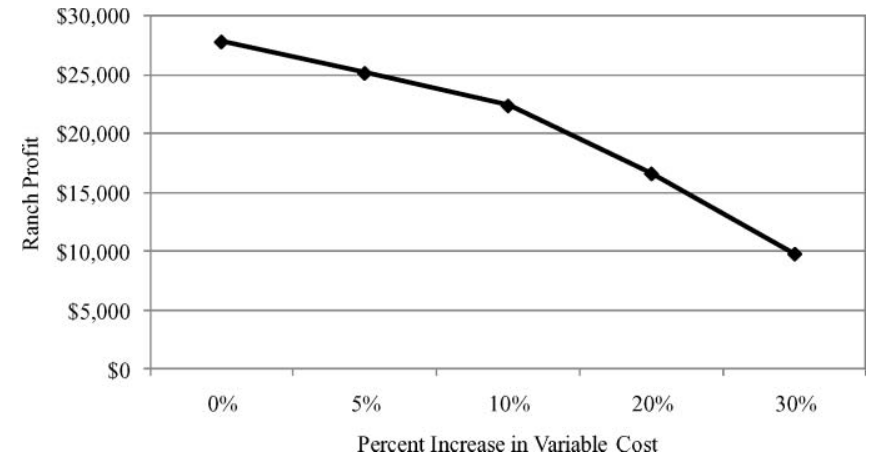

Figure 3. Effect of increased variable costs on ranch profits estimated with a ranch-level mathematical programming model. Percent increases in variable costs measure potential predation-induced increases relative to the model baseline (0\%).

decreased from 610 to 539 . Similar to the other scenarios, hay sales increase by $69 \%$ (169 to 285 tons), offsetting some of the increase in variable cost. The percentage of negative years increases only slightly over the model runs in this scenario until variable costs increase by $20 \%$ or more. Relative to the death loss and reduced weaning weight scenarios, the simulated changes in variable costs have relatively small effects on ranch profits. Profits are not significantly affected until variable costs increase by $20-30 \%$, which likely exceeds reasonable ranch-level predator expenditures.

\section{Summary and Implications}

We examine the potential impacts of predation on ranch profits using a representative ranch model consistent with a western Wyoming cow-calf operation. We use the ranch model to simulate three alternative mechanisms by which predation can impact profits: increased death loss, decreased weaning weights, and increased variable costs. The results suggest that predation can have significant impacts on both short-term profitability and long-term viability depending on the mechanism.

Of the three scenarios, increased variable cost has the least effect on ranch profits. Increased death loss takes a larger toll on profits because it erodes the ranch's core profit center, calf sales. Thus, even though the ranch maximizes production of calves at sufficient weight, the removal of calves by predators decreases profits because fixed costs remain the same. Reduced weaning weights, however, had the largest effect on profits. This likely occurs because our model assumes that all calves experience lower weaning weights as a result of predator pressure. That is, unlike death loss, where the calves are still profitable and only quantity is reduced, reduced weaning weights make all calves less profitable. Furthermore, as in the death loss scenario, fixed costs remain the same and must therefore be absorbed by calves that generate lower revenues.

The results have important implications for ranch-level management. The result that increasing variable costs have less of an effect on profitability than death losses or reduced weaning weights suggests that individual efforts to reduce predation may be economically efficient. Specifically, a variable cost increase of $5 \%(\$ 1,385)$ was shown to decrease profits by $\$ 2,676$. Predator control activities would only need to reduce death loss due to predators or reduce predator impacts on weaning weights by approximately $1 \%$ to be economically efficient. Which predator management activities can accomplish this remains an open question.

Additionally, our model suggests that high rates of predation can threaten the long-term viability of Western ranches. The viability of these ranches is an important public policy concern due to the many ecosystem services they provide (e.g., open space and wildlife habitat). Moreover, predation rates are likely to be relatively high in regions where ranch land is most likely to be converted to exurban development, such as in the Greater Yellowstone Ecosystem. The relationship between predation, ranch viability, and the ecosystem services ranches provide may justify public spending on predator control. In 2005, state and federal agencies spent approximately $\$ 4$ million on predator control in Wyoming. Yet, no study has systematically examined whether these annual expenditures effectively protect ranchland or whether they preserve the public interest in private ranches.

Lastly, this exploratory analysis also highlights the need for additional research in several areas. First, although there are existing studies and available data on death loss attributable to predators, there are few scientific data describing predation impacts on livestock weaning weights in the Western range livestock system. Given the sensitivity of profits to weaning weights, a better understanding of the relationship between predator pressures and weaning weights (if any) could have important implications for regional and ranch-level predator management programs. Additionally, we only considered the effects of death loss and weaning weights in isolation. It is possible that these effects are cumulative (i.e., the combined effect is greater than the sum of each individual effect). Cumulative effects between these mechanisms could generate important thresholds for ranch profitability, yet we are unaware of any scientific studies that explore this possibility. In the absence of field studies, surveys or interviews with representative producers could shed more light on how these mechanisms operate at the ranch level.

\section{References}

1. National Agricultural Statistics Service. 2006. Cattle death loss. Washington, DC, USA: Agricultural Statistics Board, US Department of Agriculture. 15 p.

2. Torell, L. A., J. A. Tanaka, N. Rimbey, T. Darden, L. Van Tassell, and A. Harp. 2002. Ranch-level impacts of changing grazing policies on BLM Land to protect the greater sage-grouse: evidence from Idaho, Nevada and Oregon. Caldwell, ID, USA: Policy Analysis Center for Western Public Lands. 23 p.

3. Taylor, D. T., R. H. Coupal, and T. K. Foulke. 2005. The economic impact of grazing in Park County, Wyoming. 
Laramie, WY, USA: University of Wyoming, Department of Agricultural and Applied Economics. 35 p.

4. Taylor, D. T., R. H. Coupal, T. K. Foulke, and J. G. Thompson. 2004. The economic importance of livestock grazing on BLM Lands in Fremont County, Wyoming. Laramie, WY, USA: University of Wyoming, Department of Agricultural and Applied Economics. 24 p.

5. Anderson, C. R., Jr., M. A. Ternent, and D. S. Moody. 2002. Grizzly bear-cattle interactions on two grazing allotments in northwest Wyoming. Ursus 13:247-256.

6. Bjorge, R. R., And J. R. Gunson. 1985. Evaluation of wolf control to reduce cattle predation in Alberta. Journal of Range Management 38:483-487.

7. Clark, P. 2007. Evaluating wolf impacts on ranch productivity and environmental quality. Boise, ID, USA: USDA-Cooperative State Research, Education and Extension Service National Research Initiative Managed Ecosystems Program. 126 p.

8. Tanaka, J. A., N. R. Rimbey, L. A. Torell, D. T. Taylor, D. Dailey, T. DelCurto, K. Walburger, and B. Welling. 2007. Grazing distribution: the quest for the silver bullet. Rangelands 29 (4):38-46.

Authors are Assistant Professor, brashfor@uwyo.edu (Rashford), Research Scientist (Foulke), and Professor (Taylor), Dept of Agricultural and Applied Economics, University of Wyoming, Laramie, WY 82071, USA. Research was funded by the Wyoming Animal Damage Management Board. 